rev.relac.int.estrateg.segur.9(2):77-99,2014

\title{
INVESTIGACIÓN COMPARATIVA TRANSCONTEXTUAL EN RELACIONES INTERNACIONALES NARCOVIOLENTAS*
}

\section{Diana Patricia Arias Henao**}

Burdeu manifestó: "consentir es aceptar, no es dominar, sino admitir la legitimidad de la dominación; no es tener el manejo de una actividad, sino reconocer el bien fundado en sus fines y las oportunidades de sus medios. En definitiva, es la duración del poder en la paz lo que constituye el más claro testimonio de aquello que es tenido como legítimo". (Naranjo, 2003:1).

\section{RESUMEN}

Este artículo tiene por objetivo profundizar en el método de investigación comparada en Relaciones Internacionales-RRII,

El presente artículo surge como producto de investigación de estudios doctorales desarrollados por la autora en el Instituto de Relaciones Internacionales - IRI, de la Universidad Nacional de La Plata, Argentina.

** Abogada litigante bilingüe, conciliadora extrajudicial en derecho, especialista en Derecho de las Telecomunicaciones de la Universidad Rosario y Magíster en Relaciones Internacionales, candidata a doctora en Relaciones Internacionales por la Universidad Nacional de La Plata. Docente de la Facultad de Relaciones Internacionales de la Universidad Militar Nueva Granada. ariashenaoabogados@gmail.com 
logrando sumar herramientas metodológicas que optimicen la investigación interdisciplinaria. Una vez realizado un recorrido profundo sobre los métodos comparativos, describiremos cómo la política norteamericana anti-narcótica es determinante en la formulación de las estrategias que aplican los de Estados Colombia y México, que aunque si bien contienen culturas diferentes, las mismas son olvidadas al compararse desde el diagnóstico transcontextual, originado como un factor exógeno.

Aportando de dicho diagnóstico, a la teoría de las RRII, los conceptos novedosos de Estados Superados y Guerras Promiscuas, que potencian la intervención norteamericana en forma de cooperación militar, reflejando la excesiva y para nada funcional estrategia unidireccional de la militarización para el tratamiento del fenómeno interdisciplinar y trasnacionalizado de la narcoviolencia. Así, la Empresa Subterránea o llícita - ESol- narco-violenta, se presenta como un actor que supera a los Estados en la consecución de los fines democráticos mediante el uso de Guerras Promiscuas y el funcionalismo que representan las plataformas mediáticas.

Palabras clave: Metodología de la Investigación, Relaciones Internacionales, Método Comparativo, Estados Superados, Guerras Promiscuas.

\title{
COMPARATIVE RESEARCH ON TRANS-CONTEXTUAL NARCO-VIOLENT INTERNATIONAL RELATIONS
}

\begin{abstract}
This article aims to deepen in the comparative research method of international relations, achieving a number of methodological tools that optimize interdisciplinary research. Once accomplished a profound travel on comparative methods, we will describe how the antinarcotics American policy is a determining factor in the formulation of strategies that apply Colombia and Mexico, which even though they have different cultures, these are forgotten when compared from a trans-contextual diagnosis, originated as an exogenous factor.
\end{abstract}

Applying from that diagnostic to the international relations theory, the innovative concepts of overcame states and promiscuous wars that enhance the American intervention in the form of military cooperation, it reflects the excessive and not very functional unidirectional strategy of militarization for the handling of interdisciplinary phenomena and trans-national narcoviolence. Thus, the underground or illegal business - ESol-narco-violent, arises as an actor that surpasses the states in achieving democratic goals through the use of promiscuous wars and the functionalism that media platforms represent.

Keywords: Methodology of investigation, international relations, comparative method, overcame states, promiscuous wars. 


\section{PESQUISA COMPARADA TRANSCONTEXTUAIS NARCOVIOLENTAS}

\section{RESUMO}

O objetivo deste artigo é o de aprofundar o método de pesquisa comparada em Relações Internacionais - RRII, com o fim de adicionar ferramentas metodológicas para otimizar a pesquisa interdisciplinar. Uma vez realizada uma profunda trajetória pelos métodos comparativos, descreveremos como a política americana antinarcótica é crucial na elaboração das estratégias aplicadas pelos Estados Unidos, Colômbia e México, e ainda que contenham culturas diferentes, essas são esquecidas quando as comparamos a partir de um diagnóstico transcontextual, originado como um fator exógeno.

Aportando de este diagnóstico para a teoria das RRII, os conceitos inovadores de Estados Superados e Guerras Promíscuas, que potenciam a intervenção americana na forma de cooperação militar, refletem a excessiva e nada funcional estratégia unidirecional da militarização para o tratamento do fenômeno interdisciplinar e transnacionalizado da narcoviolência. Assim, a Empresa Subterrânea ou ilícita - Esol- narco-violência, apresenta-se como um ator que supera os Estados Unidos na consecução dos fins democráticos mediante o uso das Guerras Promíscuas e do funcionalismo que representa as plataformas mediáticas.

Palavras-chave: Metodologia da Pesquisa, Relações Internacionais, Método comparativo, Estados Superados, Guerras Promíscuas.

\section{INTRODUCCIÓN}

La metodología de la investigación pretende facilitar el camino del investigador, que lo conduce sin dilatarse en el proceso mediante el uso de conceptos definidos como objetivos de investigación y sus mecanismos o, valga la redundancia, los métodos investigativos.

En el campo de las ciencias blandas en general se debate constantemente la posibilidad de generación de teorías. El mismo escenario se ha repetido en el campo de las RRII. No obstante, contemporáneamente se ha consensuado el establecimiento de tres paradigmas, pero la aplicación de los mismos no ha terminado con el flagelo narcoviolento.

La investigación en RRII, que agrupa los estudios interdisciplinarios de historia, política, economía y derecho internacional, "depende en gran medida de un conjunto de decisiones y acciones que, especialmente en el ámbito de las disciplinas humanísticas, requieren de lo que Polanyi clasificaría como conocimientos personales. La investigación se puede aprender, pero no solamente a través de un curso de aprendizaje, sino por medio de la experiencia" (Piovani, 2001, p.97). 
A la vez, autores como Smelser y Lipjhart han generalizado dentro de la metodología de la investigación que se surte en campos de las ciencias humanas, blandas o inexactas, al método comparado, como el método predilecto o específico de investigación que conlleva a la demostración de una hipótesis propuesta, permitida tal demostración por la previa enunciación de variables. La comparación consiste en una confrontación entre estados de dos o más objetos sobre una misma propiedad o propiedades. Por lo tanto, "cualquiera que sea el diseño experimental, recurrir a la comparación resulta inevitable" (Piovani, 2001, p.97).

En términos prácticos, la comparación de la estrategia narcoviolenta made in USA, aplicada sin diferencias en Colombia y México, no ha impedido la constitución de las ESol narcoviolentas como un tipo de economía "asociada con actividades al margen del código legal de un país, debido al alcance que tiene la economía del narcotráfico y la economía informal evasora de la legislación fiscal y laboral" (Arango, 2004, p.2).

\section{CLASES DEL MÉTODO COMPARATIVO Y SUS ELEMENTOS}

Los elementos del acto de comparación (objetos, propiedades, aspectos temporales) permiten discriminar entre la comparación sincrónica y la comparación diacrónica. La comparación sincrónica no atiende al aspecto temporal debido a que considera como único a los diferentes momentos temporales en el acto de comparación. Por el contrario, la comparación diacrónica, en su estadio más sencillo, atiende el acto de comparación en momentos temporales distintos. La comparación diacrónica más avanzada o "compleja es aquella en la que se consideran un objeto, dos propiedades y puntos de tiempo" (Piovani, 2001, p.99).

Conforme lo expresado, "Swanson critica la expresión investigación comparada en cuanto ella implica que existan investigaciones no comparadas" (Fideli, 1998, p.18). De esta manera se vislumbra que, "la pluralidad de formas que puede asumir la comparación y de fines por los cuales se puede comparar ha inducido a algunos estudiosos a afirmar que es imposible realizar alguna actividad cognitiva sin recurrir a la comparación. En consecuencia, toda actividad científica debería considerarse comparada" (Fideli, 1998, p.13).

Logrando identificar la ciencia de otra formación de conocimientos. No sería posible, entonces, investigar científicamente sin comparar. Esta posición de los autores, en la práctica, resulta estrecha para la creación de conocimiento en ciencia política.

Una investigación no se reduce a la comparación entendida particularmente como "acto singular de conocimiento" (Piovani, 2001, p.99). Un sector de la doctrina, ha definido la expresión comparada a las investigaciones sociales que la comprenden como un sistema global no singular. Sistemas globales que "emplean datos referidos a sociedades, culturas o naciones diferentes" (Fideli, 1998, p.18). 
Es inoportuno dar relevancia mayor a elementos investigativos que como la comparación ${ }^{1}$ hacen parte de un sinfín de medios, que son utilizados o no por los investigadores, puesto que la independencia de los casos nos recuerda que cada cual es único e independiente de la posible variedad de estrategias que se empleen para abordarlo, por lo tanto, los investigadores rígidos mal hacen en desechar la construcción original del conocimiento de un investigador empírico porque, aunque no comparta su visión, la misma hace parte de la compleja realidad que existe en el mundo. Valga establecer que la razonabilidad debe preceder los pensamientos en cuanto al entendimiento de no cuestionar las ideas fundamentales, para no proceder a un estudio meramente filosófico.

Entonces, el dominio de conocimiento es personal y no se puede pretender conocer el comportamiento humano como definición única y estática, lo cual iría en contravía, de la esencia de la vida, que es el contexto humano. Mucho menos el compartimiento de los Estados que componen a la sociedad internacional.

De esta manera las tensiones paradigmáticas se presentan para quedarse y mutar, puesto que existen elementos que a su vez son válidos para el estudio de un caso e inválidos para otro, un problema similar al que representa la equivalencia en la comparación. La conducta humana, tanto a nivel individual como grupal, se modifica respecto de los aspectos espacio-temporales, en los cuales se desarrolla o existe.

Para mantener razonabilidad y equivalencia es necesario determinar claramente la estructura metodológica y definir las estrategias que se utilizarán para delimitar el abordaje empírico ${ }^{2}$ (Lijphart; 1971, p.70) que produce conocimiento original y concluye con el proceso disciplinado del investigador que se desarrolla en el tiempo y varía conforme se surta la toma de decisiones prácticas que haga este y que le determinan el ejercicio de las mismas.

\section{EPISTEMOLOGÍA DE LA COMPARACIÓN}

Por otra parte, autores como Fideli y Marradi han definido desde el punto de vista epistemológico a la comparación como aquella operación cognitiva a través de la cual se cotejan los estados de uno o más objetos sobre la base de al menos una propiedad de los mismos, encontrando como elementos de la comparación epistemológica, los siguientes:

a. Objeto: sujetos, grupos, instituciones.

b. 1 o más propiedades.

1. La comparación está inserta en cualquier investigación científica.

2. Ya desde 1960, Lijphart sostuvo que la "actividad científica busca establecer relaciones empíricas generales entre dos o más variables... manteniendo constantes todas las otras. 
c. Estado de los objetos sobre la propiedad.

d. Tiempo específico donde se revelaron los estados.

El planteamiento anterior resulta muy amplio para demarcar los linderos investigativos, puesto que el mismo, como criterio catalizador, diluye su utilidad en la investigación científica. La comparación es una operación mental existente en todas las estrategias metodológicas de construcción y justificación del conocimiento.

Como lo advertimos, otra vertiente de estudiosos le ha otorgado a la comparación la calidad de método científico; además, en cuanto a la ciencia política y a las RRII se refiere, la comparación parece ocupar el lugar protagónico en las investigaciones que se realizan.

Una u otra concepción reflejan simplemente unas tendencias mayoritarias respecto al abordaje de la conducta humana social, diseñadas para acercarse a un estudio; sin embargo, parece que el método empírico comparativo no puede llegar a estereotiparse en el sentido rígido de ser la solución aritmética exacta que ha venido buscando irracionalmente la historia de la humanidad, para validar el comportamiento cambiante, libre y sui géneris, tanto del individuo como de su interacción con sus pares y sus dispares, refiriéndonos al poder como la propiedad que los semejanza o diferencia.

Contemporáneamente "la idea más comúnmente admitida, al menos dentro del mundo occidental, es aquella que ve en la convergencia de las aspiraciones del grupo y de los objetivos del poder, el fundamento de legitimidad de este" (Naranjo, 2003, p.123). En occidente: democracia y lucha anti-narcótica.

\section{LOS ENFOQUES COMPARATIVOS: IDEOGRÁFICOS, INTERPRETATIVOS Y DIFUSIONISTAS}

Respecto de la tipología expuesta por Marradi, relativa a los fines cognitivos de la comparación científica, revisten de importancia los siguientes enfoques comparativos y cuya orientación es de investigación cualitativa, puesto que permite el uso de una gran variedad de estrategias, en cuanto a la relación que se presenta entre los objetos estudiados:

a. Enfoque comparativo ideográfico: coteja configuraciones causales del fenómeno observado para señalar su especificidad y así proceder a comprenderlo, iniciando desde las particularidades de cada proceso histórico. Los objetivos primarios que pretende conseguir este enfoque, buscan explicar la naturaleza del fenómeno que se observa y reconstruirlo comprensivamente, esto es, identificando e indagando en torno a las causas explicativas del mismo. 
b. Enfoque comparativo interpretativo: confronta representaciones culturales diversas. Mediante la comparación se analizan las diferencias culturales, tratando así de comprender las diferentes culturas desde la perspectiva misma de sus actores. Esta tipología de estudios resulta pertinente para los de contenido constitucional, puesto que son etnográficos. Un aspecto fundamental lo contiene el etnocentrismo en RRII, que puede ser positivo o negativo, dependiendo de sus efectos producidos en la convivencia armónica internacional y de la equivalencia que se emplee efectivamente, es decir, sí es posible eliminar el personalismo al momento de diseñar el camino metodológico, adecuando las emociones del investigador dentro de un esquema neutral que permita la entrada de otras culturas al estudio, sin preferir el aspecto dentro del cual se fundamenta el contexto donde se desarrolla o desearía desarrollarse el investigador.

c. Enfoque comparativo difusionista: pretende establecer cómo lo colectivo se difunde de un contexto determinado a otro(s). Puede entenderse la difusión más claramente pensando en instituciones, tendencias culturales, estructuras de funcionamiento políticas, económicas, financieras, administrativas, servicios de telecomunicaciones, entre otras formas posibles de difusión. Por ejemplo, la mediatización internacional de los métodos de combate a la ESol narcoviolenta.

Entonces, "la comparación puede ser empleada en la ciencia con diversas finalidades" (Piovani, 2003, p.100). Por lo que, "finalmente, parece legítimo afirmar que tampoco se pueda desarrollar un estudio de caso sin realizar comparaciones... el estudio de los cambios del caso observado a lo largo del tiempo implicará alguna forma de comparación" (Piovani, 2000, p.3).

Igualmente, es importante resaltar que, tratándose de campos sociales, "la comparación se emplea con fines ideográficos o interpretativos" (Piovani, 2001, p.101). O difusionistas. Los cuales, para el estudio de las RRII resultan apropiados, pero no exclusivos.

\section{ESTUDIOS TRANSCONTEXTUALES: CROS-NACIONALES Y CROS-CULTURALES}

Una comparación tildada de mayor especificidad es la llamada comparación transcontextual, que comprende dos tipos de investigaciones que se surten, en gran medida, en el campo de las ciencias sociales, a saber:

a. Estudios cros-nacionales: parten del significado francés de Estado-nación como unidad política administrativa y con prevalencia en la presencia de la figura de la descentralización territorial.

En RRII, generalmente se presentan estudios claros, encasillados dentro de esta tipología específica de comparación, puesto que generalmente tienden a comparar unidades de 
análisis, resultando estudios cross nacionales descriptivos o explicativos, pero sin contar con elementos técnicos de investigación, tal vez, por la dualidad del campo en que se desarrolla el objeto de estudio: las humanidades.

Así, "la investigación cross-nacional ${ }^{3}$ se enmarca en un tipo genérico que podríamos clasificar como investigación comparada... (resultando) más apropiado reservar el rótulo de investigación comparada solo para casos como el de los estudios cross-nacionales" (Piovani, 2001, p.98).

b. Estudios cros-culturales: "el énfasis principal de la investigación cross-cultural es la identificación de similitudes y diferencias en conductas o conceptos en distintas culturas" (Olavarrieta, 1990, p.58).

Este tipo de investigación resalta lo importante de generalizar equitativamente aspectos universales que aporten al entendimiento del comportamiento humano, pero no a su rígida clasificación. De esta manera, "los investigadores cross-cultural deben estar informados de la necesidad de ir más allá de la mera descripción o comparación de resultados, y avanzar a fases de explicación o de teorización respecto a los por qué de estas diferencias" (Olavarrieta, 1990, p.74).

No obstante, como se ha venido expresando, que a la comparación se le haya tildado por un gran sector de la doctrina como el método específico, útil o distintivo de las ciencias sociales, la comparación como acto cognitivo no encuentra unos linderos bien definidos, lo que conlleva a que otro sector de la doctrina la considere como inconclusa en términos de utilidad referido a desarrollos investigativos.

\section{FLEXIBILIDAD EN LA CREACIÓN DE CONOCIMIENTO CIENTÍFICO HUMANO}

La sociedad internacional contemporánea carga inmersa la peligrosa tendencia que conlleva "toda generalización. Encasillar a una persona en modelos rígidos, en tipos de conductas, es olvidar la mutabilidad de comportamiento del hombre: el deseo, la inclinación o el pensamiento de hoy, no tiene que ser el de mañana. El ser humano tiene la capacidad de autodeterminarse" (Suárez, 2004, p.7). Así mismo, se generaliza en la lucha armada contra la narcoviolencia, que ha generado, el incremento y perdurabilidad de los daños colaterales, así como la mutación de los grupos ESol narcoviolentos, que rápidamente se adaptan a los escenarios que plantean los Estados y el sistema mundo.

La compleja capacidad de aceptar o no, de elegir consentir o combatir. Sin embargo, "las generalizaciones son un importante punto de partida... en el campo de los estudios

3. Comparación entre Estados. 
transculturales, las generalizaciones se tornan destructivas cuando degeneran en estereotipos. Las generalizaciones están abiertas a la revisión y al cambio; los estereotipos son sistemas de creencias cerrados" (Brake, 1995, pp.44-45).

La generalización, en términos culturales, permite ver que "cada cultura es diferente y que sus grados y las razones de obediencia al poder político son propias y particulares y no son iguales a otras, o a lo sumo similares" (Suárez, 2004, p.8). Por esto, es imprudente e inconveniente plantear las mismas estrategias contra el narcotráfico en Estados con culturas diferentes.

Resultando útil "analizar, en una perspectiva histórica y teniendo en cuenta las relaciones de poder/reconocimiento, la manera como los actores construyen sus identidades" (Ulloa, 2001, p.9). Por consiguiente, es importante considerar la posibilidad de construcción de narcoidentidades trasfronterizas.

En el campo de los negocios, autores también han manifestado importante preocuparse acerca del abordaje objetivo y óptimo que requiere una investigación, y de uno de ellos es posible destacar algunos de los aspectos expuestos y asimilarlos dentro de los estudios comparativos. Se ha definido, entonces, que el tipo denominado "cross-cultural se refiere a la investigación de un fenómeno o teoría, comparando al menos dos culturas diferentes" (Olavarrieta, 1990, p.55).

En tal sentido, "los términos investigación cross-cultural o cross-national pueden considerarse un tanto más específicos en relación con el término investigación comparativa, pues indican claramente que la variable independiente examinada para explicar diferencias en resultados, es la nación o cultura" (Olavarrieta, 1990, p.57). Dejando por sentando que el narcotráfico no es un asunto exclusivo de seguridad sino de marcada dinámica transcultural.

En consecuencia, "la legitimidad puede ser una, pero las razones en que se fundamenta cambian (García, 2000; 24), de acuerdo con la concepción cultural y antropológica de cada sociedad" (Suárez, 2004: 3). Por ejemplo, desde la cultura oriental se ha criticado "la idea estadounidense de exportar su cultura política a países en desarrollo, en donde pretende importarla rápidamente, sin considerar si hay aceptación o no por parte de los destinatarios" (Chua, 2003, p.1). Tal y como lo que se refleja en la práctica del Plan Colombia-PatriotaConsolidación y la Iniciativa Mérida, extirpantes militares de culturas cocaleras, por ejemplo.

\section{NARCOMEDIATIZACIÓN DE LAS RELACIONES INTERNACIONALES}

Tal y "como señala Fitzgerald, el concepto de identidad puede ser un puente entre los estudios de comunicación interpersonal y de masas. Aunque este concepto parece estar más próximo a la comunicación interpersonal, no se puede ignorar la influencia de los mass media en los procesos de identificación" (Alsina, 2010, p.1). 
Los discursos de los medios de comunicación proporcionan modelos de identidad a diferentes niveles: personales, colectivos, profesionales, subculturales, culturales, etc. Estos modelos que se muestran a los espectadores les ayudan a formar o a renegociar su identidad. En consecuencia, el mass media es en 2014 el principal constructor de los estereotipos culturales y de la identidad cultural (Alsina, 2010, p.1). Los discursos mediáticos principales que se utilizan en RRII, respecto al narcotráfico, son: su combate armado o la legalización de las sustancias narcóticas declaradas ilícitas.

En 2014 como alternativas de transformación de la política internacional hegemónica de los EE. UU., se analizan dos tipos de legalizaciones del fenómeno narco: legalización del consumo y legalización de la producción. Lo que requiere una diferenciación entre las sustancias y entre el consumo y el consumo indebido o endémico que causa "toda una serie de problemas sociales que, a su vez, lo impulsan, entre los que se destacan la violencia, la delincuencia organizada, la corrupción, el desempleo, la mala salud y la educación deficiente, en una espiral nefasta de daño individual y colectivo" (JIFE, 2011, p.1). Sin olvidar que, en diversas ocasiones, los actores de la narcoviolencia y de la violencia legítima usan la droga para ser verdaderos señores de la guerra.

Sin embargo, dichas alternativas generan diversas reacciones insospechadas, por ejemplo, "lo que anhelan los productores de coca es algo que no pueden decir abiertamente: la preservación del actual estado de cosas, caracterizado por la condena retórica y la prohibición formal - legal" (Mansilla, 2008, p.1), puesto que esto les asegura un ingreso mucho mayor que como actividad legal, pues paga los riesgos de amenazas y penalización. Una contradicción cultural reflejada en la querencia de las comunidades cocaleras.

\section{INVESTIGACIÓN EN RELACIONES INTERNACIONALES CON VARIABLE CULTURAL INDEPENDIENTE}

La variable cultural se encuentra a la vanguardia de los estudios contemporáneos en RRII. La misma puede cotejarse con las situaciones que se debaten en la teoría de la interdependencia, debido a la marcada presencia de factores exógenos, tanto en los planos culturales como económicos. Imposiciones culturales y económicas que marcan las RRII asimétricas. Formatos que se imponen sobre otros, tanto en la sociedad internacional como al interior de los Estados.

Lo mismo sucede en cuanto a los discursos intermésticos predominantes referidos a la lucha armada contra el narcotráfico o a la posibilidad de la legalización del comercio, ahora calificado como ilícito, en aras de reducir los daños colaterales que el combate fratricida ha representado en materia de DD. HH. en Colombia y México, y en otros Estados con culturas opuestas, que desbordan el objeto de nuestro escrito, como Afganistán y Perú.

Es decir, la teoría de la interdependencia económica sostiene que para que exista un país desarrollado debe existir uno subdesarrollado. En materia cultural, referiría el mantenimiento 
de una cultura basada en el exterminio paulatino de otra. Y en cuanto al narcotráfico, se traduciría en un linkage narcoviolento: el posicionamiento de la cultura anti-narcótica sobre la que pretende legalizar el narco-mercado.

Ahora bien, durante la década del 60, autores latinoamericanos como García Canclini, entre otros, formularon la teoría de la dependencia y del imperialismo. Estas teorías critican la teoría del desarrollo que, desde los años 50, consideraba a los medios de comunicación instrumentos para el progreso de los pueblos y por ello propugnaba la libre circulación de todos los productos comunicativos industriales. En los años 60, también se rompe la visión etnocéntrica que consideraba que el problema del desarrollo podía solventarse aplicando mecánicamente el sistema político y económico occidental en el tercer mundo" (Alsina, 2010, p.1).

Por lo tanto, conocer el aspecto cultural de cada sociedad con sus diversas vertientes "puede permitir entender los fundamentos de la legitimidad en cada sociedad... igualmente, en las sociedades con diversidad étnica y cultural debe existir un verdadero consenso político que dé soporte legítimo al propio Estado" (Suárez, 2004, p.9).

Constituyéndose la comunicación intercultural en una clave metodológica para el estudio de las RRII narcoviolentas, pues "parte del principio de la dificultad o imposibilidad de comunicación entre los implicados... empieza con la percepción de las diferencias que sugieren que los participantes a menudo no comparten normas, creencias, valores y ni tan siquiera modelos de pensamiento y conducta" (Alsina, 2010: 15). En la comunicación intercultural mediada se pueden dar "contextos de recepción muy dispares y que nada tengan que ver con el contexto de producción del mensaje" (Alsina, 2010, p.12).

La obstaculización intencional de las élites de poder al momento de ejercer el derecho contemporáneo de doble vía a la comunicación logra que la opinión pública nacional e internacional se polarice peligrosamente, generando una plataforma mediática que coadyuva a una cultura democrática occidentalizadora y antinarcótica, en ocasiones armada, que se adueña de la conceptualización en el marco de los estudios de las RRII narcoviolentas, imposibilitando establecer otro tipo de diagnósticos contra la ESol narcoviolenta, al omitir relaciones entre variables empíricas que requieren "la verificación de los estados del objeto estudiado... lo que no puede lograrse sin recurrir a la comparación" (Piovani, 2001, p.102). En palabras más sencillas, la generalización de la estrategia occidental armada contra el narcotráfico omite la variable cultural de cada Estado Superado, que termina gestando la misma estrategia militar exógena sin atender a sus factores endógenos.

Las comparaciones, que más allá de constituirse como el método esencial, resultan un elemento ineludible. Por ejemplo, comparar sistemas complejos con características similares. La comparación entonces es una operación cognitiva integrada que coadyuva al desarrollo y culminación teleológica de una investigación. La comparación del Plan Colombia y la Iniciativa Mérida permiten describir la influencia norteamericana, en cuanto a las luchas 
contra el narcotráfico se refiere, que se surte en territorios de Estados Superados por grupos de ESol narcoviolentos. En caso de no aceptar las estrategias militaristas y plaguicidas, como las fumigaciones indiscriminadas aéreas, los Estados de Colombia y México sufrirían consecuencias políticas y arancelarias y correrían el riesgo de la descertificación.

Ahora bien, la argumentación que fundamenta la "legitimidad del poder político varía según el ámbito cultural de cada sociedad. Las razones para que una cultura consienta al poder responden a circunstancias propias, y esto hace que las motivaciones de la obediencia política no tengan por qué coincidir con las de los otros conglomerados sociales" (Suárez, 2004, p.1).

La realidad internacional conlleva el estudio de aspectos técnico-metodológicos y el estudio de aspectos filosófico-epistemológicos, lo cual hace prever la dualidad de versiones sobre una misma realidad, lo que puede entenderse más claramente como los aspectos ontológicos y los aspectos deontológicos de una investigación determinada.

\section{DESINFORMACIÓN: METÁSTASIS DEL SISTEMA METODOLÓGICO EN RELACIONES INTERNACIONALES}

Continuando la ejemplificación de los estudios culturales, la desinformación produce el riesgo al investigador de "ver las cosas únicamente desde el ámbito cultural al que pertenece... puede llevar a pensar que solo las ideas, valores y conductas, allí nacidos, gozan de veracidad y validez... de esa forma, se le da con ligereza universalidad a los principios democráticos de una sociedad" (Suárez, 2004, p.3).

Los aspectos internos culturales en RRII vislumbran la diversidad cultural existente en cada Estado nacional. "El reconocimiento y respeto de la diversidad cultural de un Estado fundamenta su legitimidad" (Suárez, 2004, p.8). Si lo anterior no ocurre, la polarización de la opinión pública nacional e internacional, se presentará en algún grado. Lo mismo en cuanto a la polarización que ocurre frente al combate o la legalización de los narcóticos.

Así, el derecho a la comunicación "afecta tanto a los que emiten como a los que reciben la información, por lo tanto, atañe al emisor y al receptor... la información es susceptible de generar conocimiento en las personas, pero también lo es producir la comunicación entre ellas. Igualmente, no se puede negar que para generar opinión pública en una sociedad se requiere una necesaria información suficiente" (González, 2009).

De esta manera, "estudios de la recepción de White ponen al manifiesto que el uso de los medios de comunicación se inscriben dentro de otras prácticas culturales cotidianas. Ser un espectador no es simplemente ser un tipo de sujeto determinado, sino que es estar en una situación de comunicación determinada que está condicionada por las propias características del sujeto y por su entorno personal y social. Es decir,... se ponen de manifiesto 
las interrelaciones entre la comunicación interpersonal y la comunicación mediada... Los estudiosos de la comunicación tienen cada día más claro la sinergia de cualquier proceso comunicativo. Ni la comunicación mediada puede no tener en cuenta la comunicación interpersonal... ni la comunicación interpersonal puede estudiarse sin tenerse en cuenta el contexto cultural y mass mediático" (Alsina, 2010).

Informar y ser informado eficazmente por medios de comunicación oficiales de difusión masiva aparece en las RRII contemporáneas como la "principal base sustantiva del Derecho a la Comunicación y uno de los pilares fundamentales del Derecho Internacional de los Derechos Humanos... signo constitutivo y emblemático del sistema democrático. Por tal motivo, no puede desentenderse de la necesidad de garantizar la producción de sentido democrático en el discurso mediático, contribuyendo a poner límites a los abusos y la manipulación del poder político-económico que tienen por fin lograr la docilidad y la inmovilidad ciudadana" (Duhalde, 2009, p.1). Ni tampoco de movilidad dirigida. Resaltemos que la comunicación mediada es en la cual ocurre una "producción mediatizada del discurso" (Alsina, 2010, p.1).

El método para desarrollar una investigación debe contar entonces con fuentes primarias y secundarias, persiguiendo la comprobación de la hipótesis que se formule mediante el empleo de la herramienta del recorte tempo-espacial respecto al objeto que se pretende estudiar neutralmente.

Y claro está, resaltando que la forma prevalente política del sistema internacional no es homogénea, por eso limita la variable política al interior de un Estado Nacional. No existe consenso cultural en la sociedad internacional, pero curiosamente sí existen pactos de normas de comportamiento comercial internacional, por ejemplo.

\section{LOS ESTADOS SUPERADOS POR LAS ESOI NARCOVIOLENTAS: EL CASO DE COLOMBIA Y MÉXICO}

Durante las últimas décadas, Colombia, México y EE.UU "se encuentran en guerra... los dos primeros casos es una guerra interna contra el crimen organizado, que está involucrando crecientemente a los países centroamericanos, en especial a Guatemala y Honduras. EE.UU. apoya estas guerras" (Rojas, 2010, pp.12-13).

Las realidades narcoviolentas en Colombia y México reflejan lo que denomino como la teoría de los Estados Superados. Aquellos Estados que, si bien no son calificados como Estados Fallidos, han sido superados por grupos narcotraficantes, autónomos, que sacian falencias estatales mediante los cuantiosos recursos que le significa su actividad ESol narco-violenta, lo que les permite asumir las funciones no desarrolladas por los aparatos jurídico-políticos estatales, en ciertos lugares del territorio soberano. Resaltando que el territorio de los Estados Superados sigue siendo soberano. Los Estados de Colombia y México controlan la mayor parte de sus 
territorios y cuentan con instituciones medianamente estables aunque también impregnadas de las actividades de las ESol narco-violentas.

Urilch Beck consideró el reemplazo de la estructura estatal por empresas multinacionales. Ahora lo que ocurre es que el actor que supera al Estado mediante su directo reemplazo es un actor ilegal y generalmente violento y despiadado. Igualmente, Beck asimiló la actuación de los grupos terroristas como ONGs de la violencia, planteamiento extensible, a los grupos narcoviolentos o narcotraficantes trasnacionales puros.

La incapacidad del Estado que plantea a nivel ambiental en la Sociedad del Riesgo (Beck; $1998,1)$ debe extenderse a las ESol narco-violentas cuya amenaza es un riesgo latente y continuo, fundamentado en los masivos fondos que manejan como multitudes de ejércitos privados. Incrementando la insuficiencia e incapacidad del Estado que pasa a ser reemplazado paulatinamente $^{4}$ (Beck, 2004, p.166) en espacios concretos del territorio. Se trata entonces del reemplazo del Estado mínimo planteado por (Nozick, 1998, p.74), que debe contratar Compañías Militares Privadas CMP y grupos para-estatales, para encargarse de la seguridad, permitiendo la violación de los derechos individuales, lo que posibilita que los habitantes busquen protegerse con estrategias ilegales. Esta opción de organización política social en Colombia y México es una realidad.

Las CMP realizan sus actividades en Estados Fracasados (Tello, 2010, p.307) y se insertan en los sistemas políticos legales de los Estados Superados. Facultan a militares "retirados el potencial para una segunda carrera... en las fuerzas armadas... temen que la expansión del mercado de las CMP dañe la habilidad... para retener a los soldados talentosos. Los contratistas de la industria de las CMP... pueden ganar entre dos y diez veces lo que ganan en el ejército regular" (Singer, 2007, p.94).

México, en 2014, parece un trazo calcado de este relato. Quedando señalada la "diferencia que existe entre soldados convencidos que pelean por la gloria y soldados más dispuestos que luchan a desgano para la ambición de otros..., lo que conlleva inutilidad de los soldados mercenarios que no tienen otro motivo para luchar por ti que el escaso salario que les pagas" (Maquiavelo en Tello, 2010, p.303).

Los Estados Superados por actores ilegales para-estatales o no estatales (dependiendo de cada grupo ESol narco-violento), como son los diversos grupos narcotraficantes, generan un nuevo desorden mundial que puede fácilmente extenderse a los Señores de la Guerra y a los actores de las nuevas amenazas, que en realidad no son tan nuevas.

4. Estructuras legales y unas formas de democracia y legitimación insuficientes. 
Las ESol narco-violentas actúan como narco-compañías armadas privadas que superan funciones estatales como la seguridad, empleo y satisfacción de necesidades básicas. Un reemplazo por brindar narco-oportunidades que eliminan la frustración de ciertas comunidades.

La frustración de los seres humanos, de manera individual o social, puede devenir en explosiones de las más diversas formas de violencia. En este caso, la consolidación de Estados Superados que no son capaces de cumplir los fines esenciales democráticos.

Estos narco-actores internacionales superan, en sectores parciales, a los Estados de Colombia y México, aprovechando la frustración de su población marginal, su deseo de ascender en la escala social y su indefensión en cuestiones de seguridad, pues si no ingresan al narco-mundo voluntariamente podrían ser exterminados o estarían condenados a la miseria terrenal dentro de la crisis y debilitamiento de los Estados-Nación. Pero también animan a sectores pudientes de la sociedad, pues las narco-utilidades son inmensas.

\section{DEBILITAMIENTO DEL ESTADO-NACIÓN Y PRIVATIZACIÓN DE LA VIOLENCIA: DE GUERRAS CLÁSICAS A GUERRAS PROMISCUAS}

El debilitamiento del Estado potencializa el crecimiento de actores no estatales que perturban "los centros de poder legalmente constituidos, lo que impone referirnos a una hipercomplejidad... Los Estados Unidos, con su enorme capacidad de despliegue de fuerzas en todo el planeta, se han trasformado, voluntaria o involuntariamente, en un perturbador mayor del orden internacional" (Tello, 2010, pp.315-317).

La disminución de enfrentamientos interestatales o guerras clásicas ha multiplicado las guerras promiscuas entre otros nuevos tipos de conflictos, caracterizados por contradecir sus "intereses encapsulados en conflictos de valores... destinados a «domesticar» determinadas áreas del mundo refractarias a la adopción de sus formas y contenidos de organización política... Esta realidad anuncia conflictos armados con todas las condiciones para devenir absolutos, es decir, conflictos por medio de los cuales se trata de imponer un sistema de valores a cualquier precio al oponente, o hacerlo desaparecer. Por sus características, son confrontaciones que tienden a ascender a los extremos en los términos de Clausewitz, cuando este se refería a acciones recíprocas, por ello es tan importante el ejercicio de un férreo control político sobre el instrumento militar, para impedir que las mismas terminen transformándose en grandes masacres debido al empleo eventual de armamentos sofisticados o de destrucción masiva" (Tello, 2010, p.318).

Sin embargo, posterior a los atentados de las Torres Gemelas en Nueva York y el Pentágono, del 11 de septiembre de 2001, puede afirmarse que se amplió la "gama de intereses de quienes hacen las guerras... grupos ilegales, con raíces o no en viejos conflictos, están armados y están violando los derechos de miles de personas solamente para ganar dinero" (El Tiempo, 2012, p.1). 
En consecuencia, debemos aclarar que la ESol narco-violenta no representa una guerra clásica interestatal conducida "en contra del ejército regular de un Estado... las viejas guerras conducidas por estados nacionales soberanos y reguladas por el derecho internacional público están siendo ocupadas por las nuevas guerras, que son conducidas por diversos actores muchas veces no estatales sin algún tipo de regulación legal (Azzelini, 2005, p.21) ... Las nuevas guerras legitiman las guerras correctas -reguladas por el Derecho Internacional Público y conducidas por estados nacionales soberanos- como ultima ratio del intento de eliminar de la faz de la tierra el horror causado por las guerras incorrectas... guerras de desintegración del Estado, como consecuencia del fracaso de una estatalidad robusta" (Munkler, 2002, p.14).

Las ESol narco-violentas en Colombia y México representan el combustible para mantener el poderío de las "nuevas guerras urbanas del siglo XXI, donde participan diversos actores que no siempre pretenden apoderarse del Estado, sino que defienden algún recurso o un territorio local, o que quizás solo intentan crear espacios de orden público para sí mismos. Que se desee llamar a esta situación una guerra o no, es otra cuestión” (Rodgers, 2010, p.2).

Por ejemplo, es un hecho probado que desde 1993 "DynCorp está presente en Colombia... junto a más de $30 .$. CMP... participa en la lucha contra las guerrillas de las FARC, el ELN y en la represión al movimiento social, aunque sus actividades son presentadas como parte de la denominada guerra a las drogas. Estas CMP están bajo contrato directo con el Departamento de Estado de EE. UU., el Pentágono o la Agencia para el Desarrollo Internacional, USAID, por lo tanto, responden a los intereses de la superpotencia. EE. UU. clasificó a Colombia como el principal conflicto interno privatizado del mundo, después de Irak" (Calvo, 2005, p.1).

En cuanto a México, se repiten los factores descritos en el caso colombiano, surgidos desde la militarización de la lucha contra el narcotráfico, generándose una "formación masiva de asociaciones paramilitares con técnicas que cientos de militares mexicanos aprendieron en los últimos años en el famoso centro de formación del ejército estadounidense School of Americas en Fort Benning, Georgia" (SOA, 2001, p.1). Adicionalmente, "la relación entre el ejército y los paramilitares es entonces mantenida por los políticos del PRI, bien sean diputados nacionales o regionales, así como alcaldes y consejeros de distrito, que financian y conducen el terror" (Castro, 1996, p.94). Los grupos paramilitares mexicanos obedecen a una estrategia definida por el Ejército y sus actividades se extienden por todo el territorio nacional, en especial, Chiapas, Guerrero, Oaxaca, Michoacán y Veracruz. No obstante, el PAN fue identificado como el partido del Chapo Guzmán.

Ahora bien, Swadesh Rana agrupó los conflictos contemporáneos en 4 categorías. La primera constituye "enfrentamientos de bloques con pocas posibilidades de ocurrencia; los de Segunda Generación asignados por las confrontaciones entre Estados (India- Paquistán, Somalia-Chad o Etiopía-Eritea, etc.); los de Tercera Generación definidos por enfrentamientos internos donde la autoridad del Estado es cuestionada por grupos organizados que buscan beneficios políticos o económicos; y los de Cuarta Generación en los cuales no hay adversarios organizados, 
objetivos establecidos, líderes y campos de batalla. Estos últimos están caracterizados por la explotación repentina de la violencia... no requieren enfrentamiento formal ni intensivo" (Tello, 2010, p.325).

Así resulta necesaria la inclusión del concepto de Guerra Promiscua, como aquella que agrupa las nuevas guerras o conflictos de Tercera y Cuarta Generación. Son las que utilizan cualquier herramienta en la consecución de sus diversos objetivos personales, pero planificados en red como lo exige el Sistema Internacional.

Por consiguiente, en una mixtura entre conflictos de Tercera y Cuarta generación "debemos incluir al terrorismo, a los movimientos insurgentes y a diversas manifestaciones de violencia urbana, vinculadas en muchos casos con reivindicaciones de carácter religioso, con el tráfico de drogas o demandas destinadas a la obtención de un beneficio económico y social. Estos elementos configuran la base de las asimetrías presentes en gran parte de las guerras contemporáneas, dando lugar a la denominación de conflictos de baja intensidad que... pueden ser de altísima intensidad para aquellos que los sufren... las guerras de liberación nacional y revolucionarias del siglo XX deben ser comprendidas dentro del marco teórico de las guerras absolutas" (Tello, 2010, pp.328-329). Y en especial, al fenómeno ESol narco-violento en Colombia y México.

\section{NARCOVIOLENCIA Y SUS MÉTODOS INTERNACIONALES DE ESTUDIO}

La narco-violencia es un tipo de violencia más. La violencia en términos generales puede ser descrita como "una manifestación primaria y ancestral de la condición humana... es necesario entender que, si bien una de las mayores fuentes actuales de conflictos y confrontaciones armadas... encuentra su origen en el debilitamiento de los Estados como actores centrales del sistema mundo, la realidad actual muestra un puñado de actores del poder mundial con gran capacidad de decisión, pero sin legitimidad, y una innumerable cantidad de dirigentes políticos y sociales con legitimidad de origen, pero escaso o nulo poder" (Tello, 2010, p.14).

Los estudios internacionales sobre la narcoviolencia como interdisciplina deben contemporáneamente partir de la base metodológica del Sistema Mundo de Wallerstein. Sistema con impronta multipolar y donde claramente la variable política predomina sobre la jurídica, asumido el sistema sobre un rol económico enraizado en el contexto de la globalización como factor de aumento de incertidumbre económica y estratégica, que omite factores endógenos imperativos, como la variable cultural, sea esta narcótica o anti-narcótica, al comparar Estados Superados con factores endógenos diversos. Para reforzar la comparación diferenciada, es posible utilizar como marco teórico para los estudios narcoviolentos contemporáneos a la teoría del caos y a la dialéctica.

Lo anterior, por considerar al fenómeno de la ESol narcoviolenta como un sistema de interacciones y actores no estatales influyentes e influenciados por las narco-utilidades, lo 
que provoca un análisis polemológico. La polemología ha sido denominada como "el estudio objetivo y científico de las guerras, como fenómeno social susceptible de observación, igual que otro cualquiera, y que por consiguiente debe constituir un capítulo dentro de las ciencias sociales y las relaciones internacionales" (Bouthoul, 1084:66), adaptando el concepto de guerra a la narcoviolencia y sus desarrollos como actores que permean la economía y, por ende, a todos los ámbitos legales. La unidireccionalidad de la militarización representa "la inutilidad de la fuerza" (Maghroori, 1982) para resolver los estados de crisis, así como la inaplicabilidad de los paradigmas clásicos a la amenaza global.

En las ESol narco-violentas de y entre Colombia y México, se repite el problema clave de las RRII: el estatocentrismo, reflejado en la unidireccionalidad de la militarización como la solución a la lucha contra el tráfico de drogas mundial, formulado por las políticas estatales de EE.UU. y seguida por Estados débiles, Colombia y México. Es necesario resaltar que la debilidad de Colombia y México frente a EE.UU. se refleja en la disparidad en ámbitos militares, económicos, políticos y sociales.

Por dicha unidireccionalidad militarista anti-narcótica, la escuela realista se queda corta para solucionar el conflicto. Pudiendo resultar con mayor campo de adaptación teórica, la escuela iniciada precisamente por la estrechez del enfoque tradicionalista mediante las concepciones de Keohane y Nye, por un lado, y de Kaiser por el otro, insistiendo en la necesidad de una alternativa paradigmática para reducir los daños colaterales de la lucha armada anti-narcótica, que ha generado mayor número de víctimas que dictaduras y guerras declaradas.

Tampoco resulta suficiente el neorrealismo, pues "el prefijo neo sirvió en cierta medida para ocultar la reafirmación de los temas tradicionales -sobre el Estado, el poder, el conflicto-, reflejo también de dos importantes cambios con respecto a la agenda anterior: por un lado, se prestaba una atención mucho mayor al papel de lo económico en las relaciones interestatales, no en los términos de los enfoques transnacionales o interdependientes sino como un instrumento, mercantilista y competitivo, del poder estatal; por otro lado, se hizo una revisión teórica, en un intento de elaborar una teoría más rigurosa" (Halliday, Fred,2000:57-58).

En consecuencia, las críticas al paradigma realista, en sus dos versiones, "descansan principalmente en su ignorancia de los procesos transnacionales y de los actores no estatales , que tienen... un papel central en... las relaciones internacionales" (Arenal, 2010, p.26) narcoviolentas.

Lo que podría significar el reemplazo parcial o especializado de los Estados Superados por actores no estatales, no necesariamente con facha de violentos, pero legitimado conforme a relaciones de negociación política, conllevando a la sistematización del reemplazo de las funciones estatales para ser asumidas por los grupos narco-violentos ilegales que desarrollan las ESol. En últimas, la conducción de la sistematización del reemplazo paulatino de lo ilegal a lo legal; la sustitución se da de manera espontánea. 
Los principales factores identificados por la doctrina que indican el statu quo de la ESol narco-violenta en Colombia y México, se traducen en: "ausencia de voluntad política para un diagnóstico multidimensional del fenómeno trasnacional; el énfasis militar ante un fenómeno multisectorial, más represivo que preventivo, con una institucionalidad involucrada en el establecimiento comercial ilegal que permite la penetración de actividades de lavado de activos, entre otros" (Cieza, 2013, p.28).

\section{CONCLUSIÓN}

La bisagra que le hace falta a la sociedad internacional globalizada es la efectividad de una información objetiva y veraz, pues destruye la anhelada plataforma democrática u otra organización política predilecta y soberana que busque la paz, mutilando la opción de comprender de una manera neutral la agenda narco-interméstica de los Estados y fomentando la polarización de la opinión pública.

En las investigaciones cross-nacionales y las cross-culturales, metodológicamente hablando, debemos enfatizar en la problemática central que se refleja en la equivalencia entre lo que se observa y lo que se describe.

La actuación de la comparación en el campo de la creación y construcción de conocimiento científico no se limita a un medio sino que se expande dentro de múltiples escenarios que se traducen en medios o recursos. Por lo tanto, la comparación puede aparecer con distintos métodos y enfoques científicos y es posible su articulación y su variabilidad en el tiempo y en diversos contextos.

Dejando para la reflexión los entramados retóricos, el modelo de desarrollo actual vulnera y amenaza constantemente con destruir la validez de los estudios en RRII por no ofrecer respuestas al fenómeno narcoviolento y su funcionalidad política manipulada a través de medios de comunicación masivos trasnacionales.

La única forma de lograr el objetivo de las RRII, es decir, lograr la paz internacional, depende indiscutiblemente de despolitizar la información que es materia prima para las investigaciones tan complejas en el campo de las RRII, pues tal vez los métodos sean efectivos, pero el suministro irreal de materiales de investigación genera diagnósticos inútiles teóricos, debido a que son poco determinantes en el estadio práctico de las coyunturas concretas que pretende examinar, describir y modificar.

Es evidente que en el fenómeno de las ESol narco-violentas convergen tipos de actores transnacionales, legales e ilícitos, cuya estatalidad resulta difusa. Las ESol narcoviolentas de matriz colombo-mexicana afectan de manera directa la economía mundial y superan a los Estados al ser generadores de empleos, así estos estén por fuera de la normatividad de los 
mismos, creando un Suborden y un Subsistema Internacional de las ESol narco-violentas que actúan sobre el orden internacional de la globalización imperante en la sociedad internacional. En el suborden y en el subsistema es necesario "delimitar la relación y coordinación entre partes (actores) y procesos (factores)... donde el factor económico puede considerarse como el factor decisivo" (García, 2000, pp.183-184), así como atender los factores culturales que generan muchas veces narco-identidades en detrimentos de los debilitados Estados nacionales.

No se "supone la negación de que las relaciones internacionales sean por naturaleza esencialmente conflictivas y puedan interpretarse exclusivamente en términos de lucha por el poder. Aunque se reconoce el carácter conflictivo, mejor, «problemático», se afirma igualmente su carácter cooperativo" (Arenal, 2010, p.26). Pero no una cooperación condicionante ni de un solo sujeto. Sería preciso concebir una verdadera política regional que adapte cada uno de los particularismos que caracterizan las ESol narco-violentas de Colombia y México.

Resultando innegable la existencia de los actores transnacionales no legales como protagonistas en la sociedad internacional "dadas las actividades a las que se dedican, el impacto social y político de las mismas y el volumen del dinero que manejan: ... pueden dividirse en dos: los grupos que desarrollan actividades delictivas tradicionales, como tráfico de armas, drogas, tráfico de seres humanos y falsificaciones... y los grupos terroristas" (Pereira, 2009, p.46).

Lo cierto es que no se ha podido acabar con el fenómeno narcoviolento con la táctica unidireccional de la militarización y la misma sigue siendo el combustible de la mutación de las diversas estructuras delincuenciales, provenientes de sectores legales e ilegales, nacionales e internacionales, que responden rápidamente a los cambios que plantean sus Estados Superados, en cooperación con el hegemón político de los mismos, los EE.UU., o simplemente los corrompen.

En definitiva, la lucha armada contra las ESol narcoviolentas en Colombia y México, que son comparadas como un mismo fenómeno, pero que si atendiera a factores endógenos más que exógenos, como las variables culturales de los mismos, generarían diagnósticos teóricos particulares que requieren de estrategias soberanas y no superadas de transformación del status quo narcoviolento.

Si no se recupera la autonomía decisional que otorga la soberanía, los Estados Superados continuarán con sus Guerras Promiscuas, alentadas por las utilidades de las ESol narcoviolentas que reproducen escenarios de constante violación de normas imperativas - lus Cogens, que en la práctica internacional siguen siendo "relaciones de negociación" (Álvarez, 1999, p.87). De otro lado, la militarización puede generar la victimización de los estados productores, resultando funcionales las estrategias made in USA, que le reportan a Colombia y México un flujo constante de miles de millones de dólares para modernizar las fuerzas armadas como única opción del combate contra el narcotráfico y sus delitos conexos, lo que reafirma su condición de Estados Superados por Guerras Promiscuas lideradas por las ESol narcoviolentas que reemplazan 
parcialmente las finalidades democráticas. Estados permisibles ante tal realidad, atendiendo factores externos, como el interés de gobiernos poderosos y sus compañías trasnacionales, en particular el de los EE. UU. como consumidor principal de drogas provenientes de Colombia y México e inversionista extranjero directo de diferentes clases de bienes y servicios, en especial los de CMP y megaproyectos comerciales, en dichos territorios nacionales.

En definitiva, pese a décadas de combate militar, el narcotráfico representa una empresa rentable y sus utilidades ilícitas permean un sinfín de crímenes internacionales, así como a las economías legales internacionales y las instituciones democráticas. Los diagnósticos soberanos y no superados podrían evitar que la cooperación se trasforme en intervención o en dominación.

\section{REFERENCIAS}

- Alsina, M. (2010). Los Estudios de Comunicación Intercultural Red de La Iniciativa de Comunicación. Revista de Estudios de Comunicación ZER, Universidad del País Vasco. Recuperado de: www.comminit.com. Consultado el 4.2.2013.

- Álvarez, J. (1999). Cambio de Jurisprudencia de la Corte Constitucional en materia internacional. La sentencia C-400 de 1998. Bogotá: Universidad Externado de Colombia.

- Arango, C. (2004). Economía Subterránea en Colombia 1976-2003: Una medición a partir de la demanda de efectivo. Colombia: Banco de la República.

- Arenal, C. (2010). Introducción a las Relaciones Internacionales. Madrid: Tecnos.

- Azzelini, A. (2005). La privatización de las Guerra\$ Paramilitares, señores de la guerra y ejércitos privados. Berlín: De Das Unternehmen Krieg, Assoziation.

- Beck, U. (1998). La sociedad del riesgo. Barcelona: Paidós.

- Beck, U. (2004). Poder y contrapoder en la era global. España: Paidós Ibérica.

- Bouthoul, G. (1984). Tratado de Polemología. Ediciones Ejército. En Tello, A. (2010). La Teoría de las Relaciones Internacionales desde un punto de vista político-polemológico. Argentina: UNLP.

- Brake, T.; Medina, D. \& Walter, T. (1995). Doing bussines Internationally, The guide to cross-cultural success. New York: McGraw-Hill.

- Calvo, H. (2005). Colombia como en Irak: Guerra privada en Colombia. Francia: Le Monde Diplomatique. 
- Castro, G. (1996). Ni paz ni justicia. Chiapas: Centro de Derechos Humanos Fray Bartolomé de Las Casas.

- Cieza, D. \& Beyreuthe, V. Economía subterránea, control social y violencia. Socialización y Violencia. Buenos Aires: ALAS - Grupo de Trabajo 28.

- Chua, A. (2003). World on fire: how exporting free market democracy breeds ethnic hatred and global instability. USA: Doubleday.

- Duhalde, L. (2009). Derecho a la información. Argentina: UBA. Recuperado de: www. catedras.fsoc.uba.ar. Consultado el 25.4.2014.

- Fidelli, (1998). Tomado de Piovani, L. (a). (2001). Los Estudios Comparativos: estrategias de investigación empírica en relaciones internacionales. Argentina: UBA.

- García, E. (2000). El estado constitucional ante su momento maquiavélico. Madrid: Cuadernos Civitas.

- García, P. (2000). ¿Qué es esa cosa llamada relaciones internacionales? España: Ed. Marcial Pons.

- González, G. (2008). El derecho de la información del siglo XXI. Recuperado de: www. elespectador.com. Consultado el 23.9.2009.

- Halliday, F. (2000). Las relaciones internacionales en un mundo en transformación. España: Catarata. Traducción de Mónica Salomón.

- Howland, T. (2012, 2 de junio). DIH en las nuevas guerras. El Tiempo. Recuperado de: www.asuntosdelsur.org/opiniones/opinion/221.Consultado el 21 de octubre de 2012.

- Junta Internacional de Fiscalización de Estupefacientes - JIFE (2011). Informe Junta Internacional de Fiscalización de Estupefacientes - JIFE. New York: ONU.

- Lijphart (1971). En Piovani, J. (b). (2000). Acerca del status de la comparación en la Ciencia Política. Argentina: UNLP.

- Maghroori, R. (1982). Introduction: Major Debates. S D E.

- Mansilla. (2008). Drogas, valores sociales y neoliberalismo: El debate en el área andina a partir de 1990. Madrid: Universidad Complutense.

- Maquiavelo, N. Discurso sobre la Primera Década de Tito Livio. S D E. 
- Munkler, H. (2002). Entrevista con Eberhard Sens. Alemania: Lettre International.

- Naranjo, V. (2003). Teoría constitucional e instituciones políticas. Bogotá: Temis.

- Nozick, R. (1998). Anarquía, Estado y Utopía. México: Fondo de Cultura Económica, traducción de Rolando Tamayo.

- Olavarrieta, S. (1990). Aspectos metodológicos en la investigación cross-cultural. Santiago de Chile: Universidad de Chile.

- Pereira, J. (2009). Historia de las relaciones internacionales contemporáneas. Barcelona: Ariel.

- Piovani, J. (a). (2001). Los Estudios Comparativos: estrategias de investigación empírica en relaciones internacionales. Argentina: UBA.

- $\quad$ Piovani, J. (b). (2000). Acerca del status de la comparación en la Ciencia Política. Argentina: UNLP.

- $\quad$ Rodgers, D. (2010). International Review of the Red Cross. USA: No. 878.

- $\quad$ Rojas, F. (2010). América Latina y el Caribe: avances retóricos sin acuerdos vinculantes. Atlas Comparativo de la Defensa en América Latina y Caribe. Colombia: RESDAL.

- $\quad$ Singer, P. (2007). La Privatización de la Guerra. Archivos del Presente, 38.

- School of the Americas (2001). Estrategias para la lucha contrainsurgente. Western Hemisphere Institute for Security Cooperation (WHISC). Recuprado de: www.soaw.org.

- Suárez, J. (2004). Fundamento de la legitimidad frente al ámbito cultural. Civilizar - Revista electrónica Universidad Sergio Arboleda. Recuperado de: http://www.usergioarboleda. edu.co/civilizar/revista9/FUNDAMENTO_LEGITIMIDAD_FRENTE_AMBITO_CULTURAL.pdf.

- Tello, A. (2010). La Teoría de las Relaciones Internacionales desde un punto de vista políticopolemológico. Argentina: Universidad Nacional de La Plata.

- Ulloa, A. (2001). El Nativo Ecológico: Movimientos Indígenas y Medio Ambiente en Colombia. Colombia: Universidad Nacional. 